\title{
Management of significant reactivation of old disciform scars in wet Age-Related Macular Degeneration
}

Rosa M Coco ${ }^{*}$ and Anna Sala-Puigdollers

\begin{abstract}
Background: Fibrotic disciform scars represent the end-stage of wet age-related macular degeneration (AMD) and ophthalmologists tend not to treat them. However, reactivation can occur resulting in further worsening of patients. The aim of this study is to describe the clinical outcomes of 10 patients with disciform scars from age-related macular degeneration (AMD) that have subsequently reactivated.

Methods: Indocyanine green angiography (ICG) was used to identify the active areas and these "hot spots" $(\mathrm{HS})$ that were subsequently treated with focal laser photocoagulation.

Results: In 10 out of 11 patients with potential reactivation of an AMD scar, a treatable HS was found on the ICG at the border of the disciform scar. The identified HS was treated with focal laser photocoagulation. Post treatment these areas became inactive. However in 2 cases, reactivation occurred requiring retreatment a few months later.

Conclusions: AMD patients who are noted to have disciform scars that are increasing in size and signs of activation such as lipid exudation and subretinal haemorrhage should undergo ICG imaging to look for HS. These patients could benefit from focal laser to stabilize the disease and avoid complications and further peripheral visual loss. It is suspected that these patients may have the polypoidal subtype of AMD.
\end{abstract}

Keywords: Age-related macular degeneration, Disciform scar, Indocyanine green angiography, Laser photocoagulation

\section{Background}

Fibrotic disciform scars are typically thought to represent the end-stage of wet age-related macular degeneration (AMD) and as such ophthalmologists tend not to treat these cases $[1,2]$. However, reactivation can occur in the periphery of disciform scars. Mild cases may result in further worsening of patients' central scotomas whilst severe cases can result in complications such as massive subretinal haemorrhage with sudden severe visual loss and significant impact on quality of life [3-5].

Laser photocoagulation was the first treatment available for active neovascular AMD [6]. Due to new antiangiogenic treatments, this therapy is no longer widely used $[7,8]$. Laser treatment remains indicated in selected cases of AMD such as extrafoveal membranes. Similarly, a reactivation at the margin of a disciform scar is

\footnotetext{
* Correspondence: rosa@ioba.med.uva.es

Instituto de Oftalmobiologia Aplicada (IOBA), Campus Miguel Delibes, University of Valladolid, po de Belén no 17, Valladolid 47011, Spain
}

extrafoveal in location and could be amenable to focal laser treatment and it could be considered to be used for this purpose. To our knowledge this is the first report proposing the management of disciform scar reactivations using ICG and focal laser photocoagulation.

\section{Methods}

Eleven patients with advanced wet AMD presented with a symptomatic reactivation of their longstanding fibrotic discifom scars involving the fovea. At this presentation the best-corrected distance Snellen visual acuity (VA) was under 20/200 in all patients and thus they were not considered to be treated with antiangiogenic drugs.

These patients underwent indocyanine green angiography (ICG), with 10 out of 11 having a "hot spot" (HS) identified.

All 10 patients with a HS were treated on the same day with focal laser to prevent further expansion of the lesion. Laser spots were applied using an Iridex Oculight 
TX $532 \mathrm{~nm}$ laser at 250-500 $\mathrm{mW}$ power. Laser pulse duration and spot size were fixed at $200 \mathrm{~ms}$ and $200 \mu \mathrm{m}$ respectively to mark the border of the lesion; and at 500 $\mathrm{ms}$ and $500 \mu \mathrm{m}$ respectively to treat the centre.

Data gathering was carried out after the Clinical Research Ethics Committee -Health Area East- of Valladolid (CEICVA-EAST-HCUV) approved the study protocol. This research followed the tenets of the Declaration of Helsinki.

\section{Results}

\section{Patient 1}

A 75-year-old female presented a reactivation of the disciform scar on her left eye (LE) with initial VA of 20/600. On examination she had a serous pigment epithelium detachment (PED) with subretinal haemorrhage and lipid exudation.

\section{Patient 2}

A 71-year-old female presented a reactivation on her right eye (RE) with an initial VA of 20/800. She had a PED with a large area of lipid exudation. Following focal laser treatment, the area remained active 3 months later and required further focal laser treatment. Four months later, clinically the AMD appeared inactive with decrease in lipid exudation and resolution of the PED.

\section{Patient 3}

A 65 year-old female presented a reactivation on her LE with an initial VA of 20/600. She presented with an area of retinal thickening with associated lipid exudation with no PED or subretinal haemorrhage.

\section{Patient 4}

A 77-year-old male presented a reactivation on his LE with an initial VA of 20/600. He presented with a large serous PED with lipid exudation. The treated area showed signs of improvement at 3 months after treatment but incomplete resolution. However by 8 months, the disciform scar became inactive. A new reactivation one year later required another session of laser.

\section{Patient 5}

A 69-year-old male presented a reactivation on his LE with an initial VA of 20/250. He presented a haemorrhagic PED.

\section{Patient 6}

A 75-year-old female presented a reactivation on her RE with an initial VA of 20/500. She presented with a large subretinal haemorrhage with lipid exudation.

\section{Patient 7}

A 76-year-old male presented a reactivation on his RE with an initial VA of 20/250. He presented with two serous PEDs with associated lipid exudation. The treated area remained active 3 months later, however became inactive 4 months later. At 12 months there was a new reactivation but this time involving a new margin of the disciform scar. The area previously treated remained inactive (Figure 1).

\section{Patient 8}

An 86-year-old female presented a reactivation on her LE wit an initial VA of 20/250. She presented a large seroushaemorrhagic PED.

\section{Patient 9}

A 79-year-old male presented a reactivation on his LE with an initial VA of 20/300. He presented with peripapillary subretinal haemorrhages.

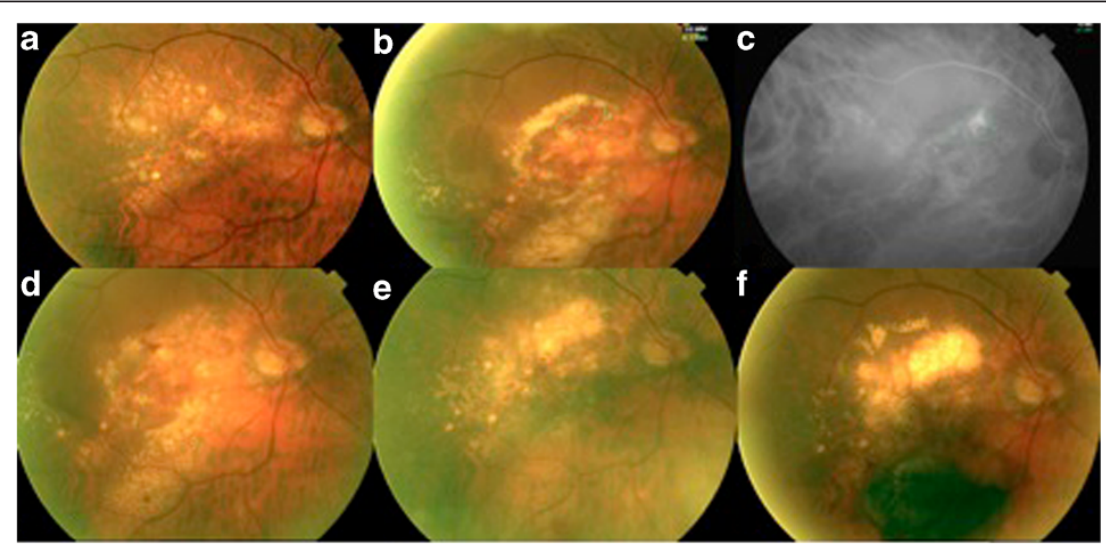

Figure 1 Fundus images from Patient 7. a. Fundus colour retinography of a disciform scar previous to the reactivation. b. Fundus colour retinography showing the reactivation of a disciform scar at its superotemporal margin with 2 big serous PEDs and lipid exudation. $\mathbf{c}$. The indocyanine green angiography shows a "hot spot" $\mathbf{d}$. Active lesion 3 months after treatment. e. Inactive lesion 7 month after treatment. PEDs and exudates had completely disappeared. f. Reactivation of a new area (haemorrage at the inferior margin) of the disciform scar one year after treatment. 


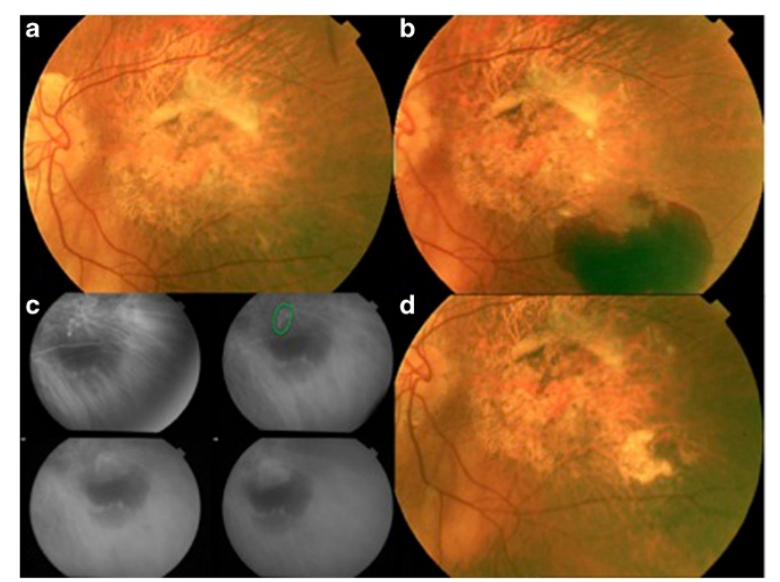

Figure 2 Fundus images from patient 10. a. Fundus colour retinography of a disciform scar previous to the reactivation. b. Fundus colour retinography showing the reactivation of a disciform scar at its inferotemporal margin with a big subretinal haemorrhage. c. The indocyanine green angiography shows a "hot spot". d. Inactive lesion 9 month after treatment. The subretinal haemorrhage had completely disappeared.

\section{Patient 10}

A 80-year-old female presented a reactivation on her LE with an initial VA of 20/500. She presented with a large subretinal haemorrhage and PED (Figure 2).

\section{Long term outcome}

Following this treatment, all patients were seen to have inactive AMD. Over the follow-up duration, 2 patients subsequently reactivated and needed retreatment (Table 1). VA was not seen to change following treatment.

\section{Discussion}

Age-related macular degeneration (AMD) remains one of the main causes of legal blindness among the population older than 65 years in developed countries [9]. Those AMD patients presenting a reactivation of a previously inactive disciform scar must be carefully observed. An ICG examination should be considered if there is new haemorrhage, exudate, or serous PED at the margin of the disciform scar. If a HS is seen on ICG, patients may potentially benefit from focal laser photocoagulation as this helps to stabilize the disease and possibly avoid additional complications such as massive haemorrhage [3,4], which would compromise further the quality of life of those patients. We think some of these patients, mainly the ones presenting serous or haemorrhagic PEDs, could have previously undiagnosed polypoidal lesions [10]. In such cases, periphery is important too [11]. Besides it has been described a non-negligible risk of vitreous haemorrhage after treatment with ranibizumab [12], and after PDT [13]. This risk is higher in patients under antiagregant or anticoagulant therapy [14], something common in elderly. Besides, the bigger the size of lesion (like the ones presented in this series), the worse the prognosis in polypoidal choroidal vasculopathy (PCV) [15].

It is accepted that laser controls a large number of eyes with extrafoveal PCV [16]. But we need to take into account potential complications of thermal laser photocoagulation that include formation of chorioretinal scars, secondary CNV, RPE tears, subretinal or sub-RPE hemorrhage and vitreous hemorrhage [17]. Moreover, laser has disadvantages such as higher recurrence rates [18], and enlargement of laser scars following laser treatment [19].

A significant number of patients were found to have HS in our series. On this basis, we recommend on-going following up of AMD patients with disciform scars to enable ICG-guided identification of potentially treatable reactivations. This proposal is a new variation in disease management as discifom scars tend not to be treated anymore.

\section{Table 1 Treatment outcome of the 10 treated patients}

\begin{tabular}{|c|c|c|c|c|c|}
\hline Patient & $\begin{array}{c}\text { Previous } \\
\text { treatments } \\
\text { yes/No }\end{array}$ & $\begin{array}{l}\text { Type and number of } \\
\text { previous treatments } \\
\text { (Number) }\end{array}$ & $\begin{array}{l}\text { Period of time in which lesion } \\
\text { became inactive after LPC } \\
\text { (number of treatment sessions) }\end{array}$ & $\begin{array}{l}\text { Total time of follow up } \\
\text { remaining inactive after } \\
\text { reaching complete inactivation }\end{array}$ & Reactivation \\
\hline 1 & No & & 2 months (1) & 19 months & No \\
\hline 2 & Yes & Ranibizumab IV (4) & 7 months (2) & No more follow up & No \\
\hline 3 & Yes & PDT (3), LPC (1) & 2 months (1) & 21 months & No \\
\hline 4 & Yes & $\begin{array}{l}\text { LPC (1), PDT (3), TाT (1), } \\
\quad \text { Ranibizumab IV(3) }\end{array}$ & 8 months (1) & 12 months & Yes (in the same area) \\
\hline 5 & Yes & PDT (1), LPC (1) & 3 months (1) & 17 months & No \\
\hline 6 & Yes & LPC (2), PDT (1) & 3 months (1) & No more follow up & No \\
\hline 7 & Yes & Ranibizumab IV (2) & 7 months (1) & 23 months & Yes (in a different area) \\
\hline 8 & No & & 5 months (1) & 27 months & No \\
\hline 9 & Yes & ПТ (1) & 3 months (1) & 12 months & No \\
\hline 10 & Yes & PDT (1), Ranibizumab IV (1) & 3 months (1) & 9 months & No \\
\hline
\end{tabular}


Some authors proposed the use of subretinal coapplication of rtPA and bevacizumab followed by repeated intravitreal anti-VEGF injections for neovascular AMD with submacular haemorrhage [3], but none of our patients had a submacular central bleeding. Instead, they had marginal reactivations of the lesion.

Concerning the possible use of anti-vascular endothelial growth factor drugs, all patients included in this series had poor vision and a longstanding fibrotic disciform scar involving the fovea, patients excluded on pivotal trials $[7,20,21]$. Also treatment was performed far away of the fovea and accepted treatment of PCV at the periphery includes laser [16]. Finally, poor response to anti-VEGF has been reported in this condition too.

Others proposed indocyanine green angiographyguided focal thermal laser treatment of fibrotic choroidal neovascularization, but finding the perfusing afferent arterioles to do the feeder-vessel treatment is only possible if dynamic ICG is available. Unfortunately this technology is not available at most general ophthalmological clinics [22].

\section{Conclusions}

Performing ICG angiography should be considered in those patients with an active disciform scar in order to look for HS since the sensitivity of this test is high. This would help identify the patients who could potentially benefit from focal laser treatment, to stabilize the disease and avoid further visual loss. It is suspected these patients have the polypoidal subtype of AMD. Limitations of our study include small sample size and lack of a control arm.

\section{Consent}

A written informed consent was obtained from all patients for publication of this case report.

\section{Competing interests}

The authors declare that they have no competing interests.

\section{Authors' contributions}

AS reviewed the patient's charts. Both authors wrote the manuscript. RMC reviewed the manuscript. Both authors read and approved the final manuscript.

\section{Acknowledgement}

We thank Jern Yee Chen for revising the English.

Received: 10 March 2014 Accepted: 18 June 2014

Published: 25 June 2014

\section{References}

1. Parodi M, Cascavilla M, Papayannis A, Kontadakis D, Bandello F, lacono P. Intravitreal bevacizumab in advanced-stage neovascular age-related macular degeneration with visual acuity lower than 20/200. Arch Ophthalmol 2012, 130:934-935.

2. American Academy of Ophthalmology Retina Panel: Preferred practice pattern ${ }^{\oplus}$ guidelines: age-related macular degeneration. San Francisco, CA: American Academy of Ophthalmology; 2011. Available at: www.aao.org/ ppp.
3. Treumer F, Roider J, Hillenkamp J: Long-term outcome of subretinal coapplication of rtPA and bevacizumab followed by repeated intravitreal anti-VEGF injections for neovascular AMD with submacular haemorrhage. Br J Ophthalmol 2012, 96:708-713.

4. Tennant MT, Borrillo JL, Regillo CD: Management of submacular hemorrhage. Ophthalmol Clin North Am 2002, 15:445-452.

5. Googe JM, Hirose T, Apple DJ, Melgen S: Vitreous hemorrhage secondary to age-related macular degeneration. Surv Ophthalmol 1987, 32:123-130.

6. Virgili B, Bini A: Laser photocoagulation for neovascular age-related macular degeneration. Cochrane Database Syst Rev 2007, 18:CD004763.

7. Rosenfeld PJ, Brown DM, Heier JS, Boyer DS, Kaiser PK, Chung CY, Kim RY, MARINA Study Group: Ranibizumab for neovascular age-related macular degeneration. N Engl J Med 2006, 355:1419-1431.

8. Votruba M, Gregor Z: Neovascular age-related macular degeneration: present and future treatment options. Eye 2001, 15:424-429.

9. Bressler NM: Age-related macular degeneration is the leading cause of blindness. JAMA 2004, 291:1900-1901.

10. Fernandes LH, Freund KB, Yannuzzi LA, Spaide RF, Huang SJ, Slakter JS, Sorenson JA: The nature of focal areas of hyperfluorescence or hot spots imaged with indocyanine green angiography. Retina 2002, 22:557-568.

11. Karagiannis DA1, Soublis V, Kandarakis A: A case of polypoidal choroidal vasculopathy: periphery is equally important for such patients. Clin Interv Aging 2009, 4:315-317.

12. Cho HJ1, Lee DW, Cho SW, Kim CG, Kim JW: Hemorrhagic complications after intravitreal ranibizumab injection for polypoidal choroidal vasculopathy. Can J Ophthalmol 2012, 47:170-175.

13. Hiramy Y, Tsujikawa A, Otani A, Yodoi Y, Aikawa H, Mandai M, Yoshimura N: Hemorrhagic complications after photodynamic therapy for polypoidal choroidal vasculopathy. Retina 2007, 27:335-341.

14. Tilanus MA, Vaandrager W, Cuypers MH, Verbeek AM, Hoyng CB: Relationship between anticoagulant medication and massive intraocular hemorrhage in age-related macular degeneration. Graefes Arch Clin Exp Ophthalmol 2000, 238:482-485.

15. Tsujikawa A, Ojima Y, Yamashiro K, Nakata I, Ooto S, Tamura H, Nakanishi H, Hayashi H, Otani A, Yoshimura N: Association of lesión size and visual prognosis to polypoidal choroidal vasculopathy. Am J Ophthalmol 2011, 151:961-972.

16. Lee MW, Yeo I, Wong D, Ang CL: Argon laser photocoagulation for the treatment of polypoidal choroidal vasculopathy. Eye (Lond) 2009, 23:145-148.

17. Yuzawa M, Mori R, Haruyama M: A study of laser photocoagulation for polypoidal choroidal vasculopathy. Jpn J Ophthalmol 2003, 47:379-384

18. Macular Photocoagulation Study Group: Persistent and recurrent neovascularization after krypton laser photocoagulation for neovascular lesions of age-related macular degeneration. Arch Ophthalmol 1990, 92:825-831.

19. Schatz H, Madeira D, McDonald HR, Johnson RN: Progressive enlargement of laser scars following grid laser photocoagulation for difuse macular edema. Arch Ophthalmol 1991, 109:1549-1551.

20. Kaiser P, Brown DM, Zhang K, Hudson HL, Holz FG, Shapiro H, Schneider S, Acharya NR: Ranibizumab for predominantly classic neovascular age-related macular degeneration: subgroup analysis of first-year ANCHOR results. Am J Ophthalmol 2007, 144:850-857.

21. The CATT Research Group: Ranibizumab and Bevacizumab for Neovascular age-related macular degeneration. N Engl J Med 2011, 364:1897-1908.

22. Cousins SW, Bearelly S, Reinoso MA, Chi SL, Espinosa-Heidmann DG: Dynamic indocyanine Green angiography-guided focal termal laser treatment of fibrotic choroidal neovascularization. Graefes Arch Clin Exp Ophthalmol 2008, 246:1677-1683.

doi:10.1186/1471-2415-14-82

Cite this article as: Coco and Sala-Puigdollers: Management of significant reactivation of old disciform scars in wet Age-Related Macular Degeneration. BMC Ophthalmology 2014 14:82. 